Journal of Organometallic Chemistry, 276 (1984) 317-323

Elsevier Sequoia S.A., Lausanne - Printed in The Netherlands

\title{
ORGANOCOPPER(I) MEDIATED SYNTHESIS OF 1-ALKENYLSILANES AND 1,3-ALKADIENYLSILANES FROM ETHYNYLSILANES
}

H. WESTMIJZE *, H. KLEIJN and P. VERMEER*

Department of Organic Chemistry, State University at Utrecht, Croesestraat 79, 3522 AD Utrecht (The Netherlands)

(Received June 5th, 1984)

\section{Summary}

Ethynylsilanes (I) are converted into $\alpha$-silyl substituted ( $Z$ )-alkenylcopper(I) compounds (II) by treatment with $\mathrm{RCu}$ reagents. The adducts II react with a variety of electrophiles to give the 1-alkenylsilanes $\mathrm{RCH}=\mathrm{C}(\mathrm{E}) \mathrm{SiR}_{3}{ }^{\prime}$ (III: $\mathrm{E}=\mathrm{H}, \mathrm{Cl}, \mathrm{Br}, \mathrm{I}$, $\left.\mathrm{CN}, \mathrm{SnMe}_{3}, \mathrm{SMe}, \mathrm{Me}, \mathrm{H}_{2} \mathrm{C}=\mathrm{CHCH}_{2}\right)$. The conversion of $\mathrm{I}$ into III $(\mathrm{E}=\mathrm{H})$ can also be effected by using homocuprates, $\mathrm{R}_{2} \mathrm{CuMgCl}$, and triorganodicuprates, $\mathrm{R}_{3} \mathrm{Cu}_{2} \mathrm{MgCl}$. The latter reagent should be used when the group $\mathrm{R}$ is methyl. An interesting 1,3-diene formation is observed on treating excess of ethynyltrimethylsilane (Ib) with $\mathrm{R}_{3} \mathrm{Cu}_{2} \mathrm{MgCl}$; this reaction involves addition of intermediary vinylcuprates to unreacted 1-alkynylsilane ( $\mathrm{Ib}$ ). The intermediary 1,3-dienyl adduct (VIIb) reacts with various electrophiles to give 1,3-dienes, $\mathrm{RCH}=\mathrm{C}\left(\mathrm{SiMe}_{3}\right)$ $\mathrm{CH}=\mathrm{C}(\mathrm{E}) \mathrm{SiMe}_{3}(\mathrm{VIIIb})$.

\section{Introduction}

The overwhelming number of reports on the use of organocopper(I) reagents shows that the reagents are excellent synthetic tools [1]. A very important property of the reagents is their ability to convert 1-alkynes into vinylcopper(I) species [2]; such a reaction provides an attractive entry into the synthesis of e.g., juvenile hormones [3].

Some time ago, we reported preliminary results on the successful addition of organocopper(I) compounds to ethynyltriphenylsilane [4]. A report appearing at the same time was concerned with ethynyltrimethylsilane [5]. The produced vinylsilanes are useful synthetic intermediates [6]. In this paper, a detailed study of the conversion of ethynylsilanes into vinylsilanes by organocopper(I) species is presented. It is shown that the choice of the organocopper(I) reagent may be crucial. Observation of an unexpected formation of a 1,3-diene is also discussed.

* Present adress: AKZO Chemie, P.O. Box 10, Deventer (The Netherlands). 


\section{Results and discussion}

General remarks. In this investigation organocopper(I) species of the types $\mathrm{RCu}$, $\mathrm{R}_{2} \mathrm{CuMgCl}$, and $\mathrm{R}_{3} \mathrm{Cu}_{2} \mathrm{MgCl}$ were used. These copper(I) species were obtained by adding the Grignard reagent $\mathrm{RMgCl}$ to appropriate amounts of $\mathrm{LiCuBr}_{2}$ (solvent. THF) at $-60^{\circ} \mathrm{C}$ and stirring the resulting mixtures for $0.5 \mathrm{~h}$ at $-60^{\circ} \mathrm{C}(\mathrm{R} \neq \mathrm{Me})$ or at $0^{\circ} \mathrm{C}(\mathrm{R}=\mathrm{Me})$. The copper(I) species were then ready for use.

$R C u$ compounds. It was found that the 1-alkynylsilane $\mathrm{Ph}_{3} \mathrm{SiC} \equiv \mathrm{CH}$ (Ia) undergoes a smooth, regio- and stereo-specific addition of $\mathrm{RCu}$ reagents when $\mathrm{R}$ is branched or unbranched alkyl but not when $\mathrm{R}$ is methyl. Protolysis of the intermediate adduct IIa (Scheme 1) gave 1-alkenylsilanes IIIa in excellent yields. The poor reactivity of $\mathrm{MeCu}$ towards alkylacetylenes is well known [2], and so its unreactivity towards Ia was not unexpected. Similar experiments with (trimethylsilyl)acetylene, $\mathrm{Me}_{3} \mathrm{SiC} \equiv \mathrm{CH}$ (Ib), gave results that were satisfactory only when $\mathrm{R}$ in the reagents used was a branched alkyl group. The use of $\mathrm{BuCu}$, for instance, gave a mixture of the desired adduct $(80 \text { rel. \%). BuCH=C(Bu)SiMe})_{3}(18$ rel. \%) and the 1.3-diene $\mathrm{BuCH}=\mathrm{C}\left(\mathrm{SiMe}_{3}\right) \mathrm{CH}=\mathrm{CHSiMe}_{3}(2 \mathrm{rel}$. \%). The mono-ene contaminant arises by coupling of the intermediary vinylcopper(I) compound $\mathrm{IIb}$ with $\mathrm{BuCu}$, and the diene by addition of adduct IIb to $\mathrm{Ib}$ (see below). The attempted addition of $\mathrm{PhCu}$ to Ia,Ib was unsuccessful.

The $\alpha$-silyl substituted vinylcopper(I) compounds are fairly stable. Vinylcopper(I) compounds usually dimerize rapidly above $-10^{\circ} \mathrm{C}$ [2], but solutions of our adducts can be stirred at room temperature during $1.5 \mathrm{~h}$ without detectable dimerization (as established for IIa). It could be that the dimerization is inhibited by steric hindrance from the silyl group.

The intermediate adducts shown in Scheme 1 react with a variety of electrophiles. Because of the pronounced thermal stability of the adducts, the presence of stabilizing agents like trimethylphosphite prior to the addition of the elelectrophile is not required. Thus, 1-halovinylsilanes were obtained by treating the intermediary adducts with $N$-chlorosuccinimide $(\mathrm{E}=\mathrm{Cl}), N$-bromosuccinimide or cyanogen bromide $(E=\mathrm{Br})$, or iodine $(\mathrm{E}=\mathrm{I})$. When methyl methanethiolsulfonate, cyanogen chloride or trimethyltin chloride were added, vinylic silanes were formed bearing a $\mathrm{MeS}, \mathrm{NC}$ or $\mathrm{Me}_{3} \mathrm{Sn}$ group in the $\alpha$-position. Allylation and methylation were carried out with allyl bromide and methyl iodide, respectively. For yields, physical constants and some ${ }^{1} \mathrm{H}$ NMR data for compounds III, see Table 1.

$\mathrm{R}_{2} \mathrm{CuMgCl}$ and $\mathrm{R}_{3} \mathrm{Cu}_{2} \mathrm{MgCl}$ compounds. Silane Ia reacted smoothly with dialkylcuprates, $\mathrm{R}_{2} \mathrm{CuMgCl}$, in which $\mathrm{R}$ is a linear or branched alkyl group. Protolysis of the intermediary adducts IVa afforded pure ( $E$ )-1-alkenylsilanes IIIa (Scheme 2).

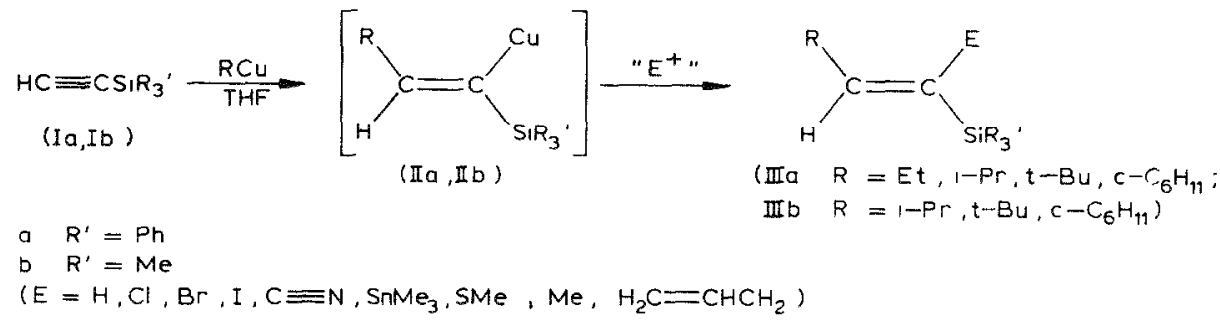


Only one of the two available groups $R$ of the cuprate was transferred at an acceptable rate. Substantial differences in rate between transfer of the first and second group $\mathbf{R}$ from such cuprates have been observed in other cases [2,7]. The fact that one of the two available groups $R$ is wasted makes the reaction less attractive than the $\mathrm{RCu}$ reaction. Nevertheless, the $\mathrm{R}_{2} \mathrm{CuMgCl}$ approach could be valuable where use of $\mathrm{RCu}$ is unsuccessful. It was shown (see above) that $\mathrm{MeCu}$ shows little tendency to add to la. We therefore attempted the conversion of $\mathrm{Ia}$ by $\mathrm{Me}_{2} \mathrm{CuMgCl}$ into the $\beta$-methyl-substituted vinylsilane, but the results were disappointing. Only minor amounts of the adduct were obtained, together with starting material and side-products. The $\mathrm{R}_{2} \mathrm{CuMgCl}$ approach in this case, therefore, does not offer any advantage over the $\mathrm{RCu}$ reaction. We then turned to the dicuprate $\mathrm{Me}_{3} \mathrm{Cu}_{2} \mathrm{MgCl}$; it was recently shown that this compound is an excellent reagent for conversion of alkylacetylenes into vinylcuprates [8]. We found that silane Ia could be converted regio- and stereo-specifically into the desired adduct IIIa $(\mathrm{R}=\mathrm{Me}$, Scheme 2$)$ by using an equimolar amount of $\mathrm{Me}_{3} \mathrm{Cu}_{2} \mathrm{MgCl}$ (yield of IIIa, $\simeq 70 \%$ )

The behaviour of silane $\mathrm{Ib}$ towards $\mathrm{R}_{2} \mathrm{CuMgCl}$ and $\mathrm{R}_{3} \mathrm{Cu}_{2} \mathrm{MgCl}$ was investigated for $\mathrm{R}=\mathrm{n}$-butyl or isopropyl. Reaction of $\mathrm{Ib}$ with an equimolar amount of $\mathrm{Bu}_{3} \mathrm{Cu}_{2} \mathrm{MgCl}$ for $1.5 \mathrm{~h}$ al $-30^{\circ} \mathrm{C}$ produced pure adduct $\mathrm{Vb}$ (Scheme 3), which on protolysis gave adduct $\mathrm{IIIb}(\mathrm{R}=\mathrm{Bu})$ in $98 \%$ yield. Adduct $\operatorname{IIIb}(\mathrm{R}=\mathrm{Bu})$ contained $7 \%$ of the 1,3-diene $\mathrm{BuCH}=\mathrm{C}\left(\mathrm{SiMe}_{3}\right) \mathrm{CH}=\mathrm{CHSiMe}_{3}$ when it was prepared by treating $\mathrm{Ib}$ with $0.9 \mathrm{~mol}$ equivalent of $\mathrm{Bu}_{2} \mathrm{MgCl}$ for $1.5 \mathrm{~h}$ at $0{ }^{\circ} \mathrm{C}$ (total yield of $\mathrm{IIIb}$ and 1,3-diene, $92 \%$ ). The ratio $\mathrm{IIIb} / 1,3$-diene dropped to $50 / 50$ when $7.0 \mathrm{~mol}$ equivalents of $\mathrm{Ib}$ were stirred with $\mathrm{Bu}_{2} \mathrm{CuMgCl}$ for $72 \mathrm{~h}$ at $20^{\circ} \mathrm{C}$ (total yield of IIIb and 1,3-diene, $65 \%$ based on two available $\mathrm{R}$ groups). The interesting diene (compound VIIb in Scheme 3) was formed almost exclusively in the reaction of $7.0 \mathrm{~mol}$ equivalents of $\mathrm{Ib}$ with the dicuprate $\mathrm{Bu}_{3} \mathrm{Cu}_{2} \mathrm{MgCl}$ for $72 \mathrm{~h}$ at $20^{\circ} \mathrm{C}$ (ratio IIIb/VIIb 4/96; total yield of IIIb and VIIb, 95\% based on transfer of all three groups $\mathrm{R}$ ); similar results were found using i- $\mathrm{Pr}_{3} \mathrm{Cu}_{2} \mathrm{MgCl}$ (ratio IIIb/VIIb 9/91; total yield of IIIb and VIIb, $91 \%$ based on transfer of all three groups $\mathrm{K}$ ).

The 1,3-dienyl intermediates VIb reacted smoothly with the electrophiles methylmethanethiol sulfonate and allyl bromide to give compounds VIIb in which $\mathrm{E}$ is $\mathrm{SMe}$ and allyl, respectively. Details of the preparation of VIIb, their physical constants and some characteristic ${ }^{1} \mathrm{H}$ NMR data are given in Table 2.

It should be mentioned that suitable conditions have not yet been found for

(Continued on p. 322)

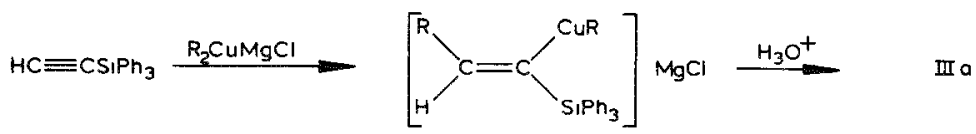

(Io)

(IDa)

$\left(R=E t, 1-P r, t-B u, c-C_{6} H_{n 1}\right)$
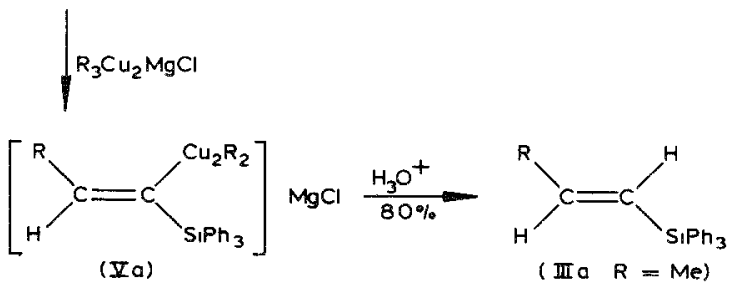

SCHEME 2 


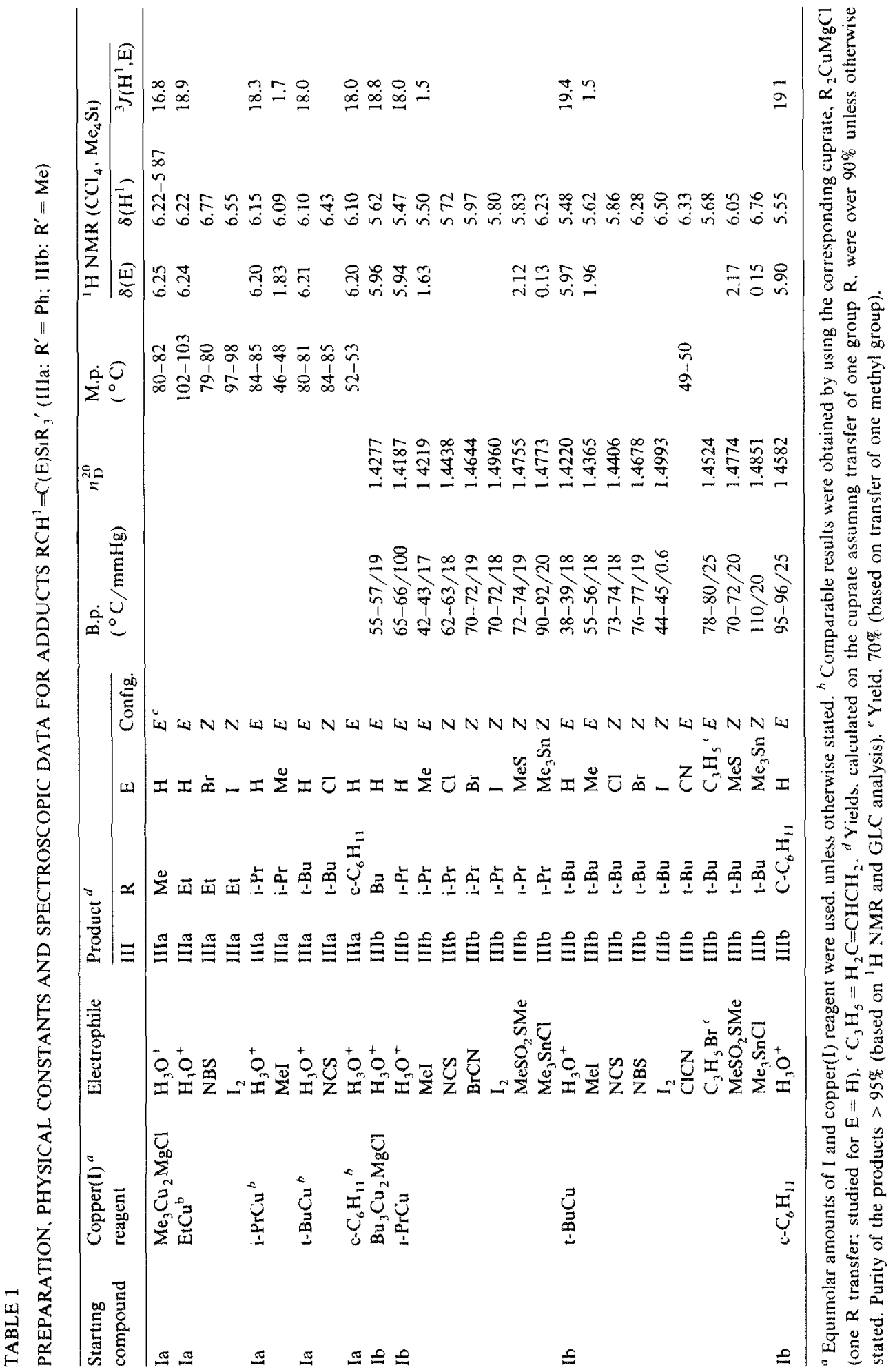




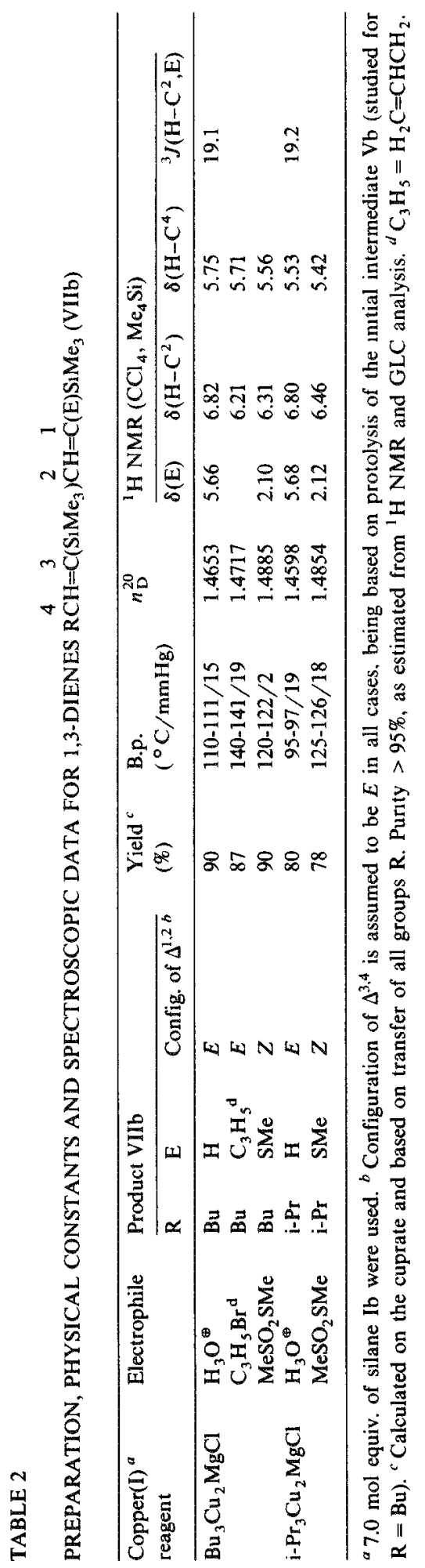




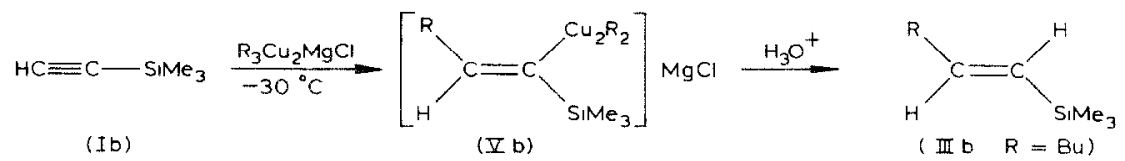

SCHEME 3

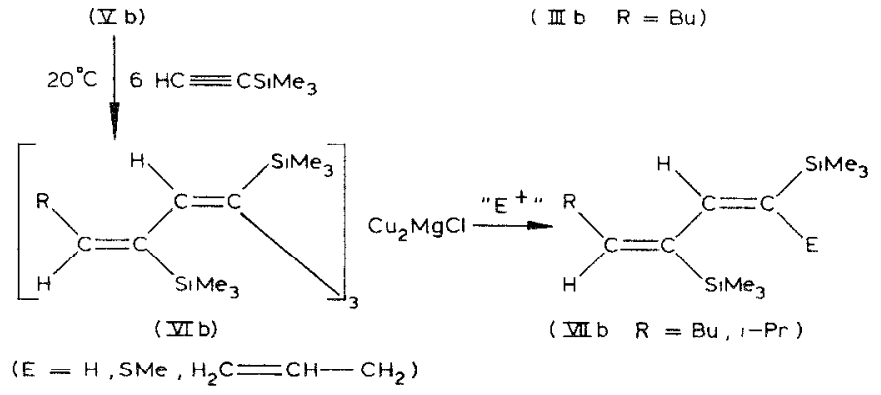

satisfactory conversion of compounds such as $\mathrm{CH}_{3} \mathrm{C} \equiv \mathrm{SiR}_{3}{ }^{\prime}$ into vinylic silanes by the routes described above. In this respect, the behaviour of such 1-alkynylsilanes resembles that of normal non-terminal alkynes [9].

\section{Experimental}

All reactions were performed under dry nitrogen. Tetrahydrofuran was distilled from $\mathrm{LiAlH}_{4}$. Grignard reagents were prepared from the organic chloride in THF; their molarity was determined by Watson's titration method [10]. Lithium bromide was dried at $220^{\circ} \mathrm{C}$ in high vacuum and was used as a $3.0 \mathrm{M}$ solution in THF for the preparation of the cuprate $\mathrm{LiCuBr}_{2}$ by mixing it with an equimolar amount of cuprous bromide. The 1-alkynylsilanes were made by the procedure described in ref. 11. ${ }^{1}$ H NMR data for the products were determined on a Varian EM-390 spectrometer.

(a). Preparation of the organocopper( $I$ ) reagents. To a stirred homogeneous solution of $\mathrm{LiCuBr}_{2}(0.01$ or $0.02 \mathrm{~mol})$ in THF $(25 \mathrm{ml})$ was added $\mathrm{a} \simeq 1.0 \mathrm{MTHF}$ solution of $\mathrm{RMgCl}\left(0.01 \mathrm{~mol}\right.$ for the $\mathrm{RCu}$ reagents, $0.02 \mathrm{~mol}$ for the $\mathrm{R}_{2} \mathrm{CuMgCl}$ reagents, and $0.03 \mathrm{~mol}$ for the $\mathrm{R}_{3} \mathrm{Cu}_{2} \mathrm{MgCl}$ reagents), at $0^{\circ} \mathrm{C}$ in the case of $\mathrm{R}=\mathrm{Me}$ and at $-60^{\circ} \mathrm{C}$ in the other cases. The resulting mixture was stirred for $0.5 \mathrm{~h}$ at 0 and $-60^{\circ} \mathrm{C}$, respectively, and the solution obtained was used as described below.

(b). Conversion of 1-alkynvlsilanes into III. To the copper(I) reagent $(0.01 \mathrm{~mol}$. see under (a)) the 1-alkynylsilane $\mathrm{I}(0.01 \mathrm{~mol})$ was added, at $-60^{\circ} \mathrm{C}$. The mixture was then stirred for $24 \mathrm{~h}$ at $0^{\circ} \mathrm{C}$ (conversion of la by $\mathrm{Me}_{3} \mathrm{Cu}_{2} \mathrm{MgCl}$ ), for $1.5 \mathrm{~h}$ at $20^{\circ} \mathrm{C}$ (conversion of $\mathrm{Ia}$ by $\mathrm{RCu}$ and $\mathrm{R}_{2} \mathrm{CuMgCl}$ ), for $1.5 \mathrm{~h}$ at $0^{\circ} \mathrm{C}$ (conversion of $\mathrm{Ib}$ by $\mathrm{RCu}$ and $\mathrm{Bu}{ }_{2} \mathrm{CuMgCl}$ ), or for $1.5 \mathrm{~h}$ at $-30^{\circ} \mathrm{C}$ (conversion of $\mathrm{Ib}$ by $\mathrm{Bu}_{3} \mathrm{Cu}_{2} \mathrm{MgCl}$ ). Protolysis of the resulting adducts afforded compounds III with $\mathrm{E}=\mathrm{H}$. Introduction of the other groups $\mathrm{E}$ into III was carried out by adding $1.1 \mathrm{~mol}$ equivalent of the appropriate electrophile at $-60^{\circ} \mathrm{C}$ to the intermediate adduct. The mixture was stirred for $10 \mathrm{~min}$ at $-60^{\circ} \mathrm{C}$, then the temperature of the mixture was allowed to rise during $30 \mathrm{~min}$ to $20^{\circ} \mathrm{C}$. Stirring at this temperature was continued for $30 \mathrm{~min}$. Work-up was carried out by pouring the mixture into an aqueous solution of $\mathrm{NH}_{4} \mathrm{Cl}$ containing $\mathrm{NaCN}(1 \mathrm{~g})$. The product was extracted with pentane/ether $(1 / 1 \mathrm{v} / \mathrm{v})$. After washing and drying $\left(\mathrm{MgSO}_{4}\right)$ of the extract, the 
solvent was stripped off. The residue was crystallized from methanol or distilled in vacuum (see Table 1). The purity of the compounds III obtained was at least $98 \%$ by GLC (SE 33 column).

(c). Conversion of 1-alkynylsilane Ib into VIIb. To the copper(I) reagent $\mathrm{R}_{3} \mathrm{Cu}_{2} \mathrm{MgCl}$ (0.01 mol, see under a) the 1-alkynylsilane $\mathrm{Ib}(0.07 \mathrm{~mol})$ was added at $-60^{\circ} \mathrm{C}$. The mixture was stirred for $72 \mathrm{~h}$ at $20^{\circ} \mathrm{C}$. Reaction of the intermediate adduct with electrophiles and work up was carried out as described for IIIb. Distillation of the crude products at reduced pressure gave compounds VIIb, with a purity of at least $98 \%$ by GLC (SE 33 column). Physical constants and other data for VIIb are shown in Table 2.

\section{Acknowledgement}

This investigation was supported by The Netherlands Foundation of Chemical Research (SON) with financial aid from The Netherlands Organization for the Advancement of Pure Research (ZWO).

\section{References}

1 For reviews, see: J.F. Normant, Synthesis, (1972) 63: G.H. Posner, Org. React., 19 (1972) 1; G.H. Posner, ibid., 22 (1978) 253; A.E. Jukes, Adv. Organomet. Chem., 12 (1975) 215; J.F. Normant and A. Alexak1s, Synthesis, (1981) 841.

2 For leading references, see: J.F. Normant, G. Cahiez, M. Bourgain, C. Chutt and J. Villieras, Bull. Soc. Chim. Fr., (1974) 1656; H. Westmijze, J. Meijer, H.J.T. Bos and P. Vermeer, Recl. Trav. Chim. Pays-Bas, 95 (1976) 299, 304; A. Marfat, P.R. McQuirk and P. Helquist, J. Org. Chem., 44 (1979) 3888.

3 H. Kleijn, H. Westmijze, J. Meijer and P. Vermeer, Recl. Trav. Chim. Pays-Bas, 100 (1981) 249, and ref. cited therein.

$4 \mathrm{H}$. Westmijze, J. Meijer and P. Vermeer, Tetrahedron Lett., (1977) 1823.

5 M. Obayashi, K. Utimoto and H. Nozaki, Tetrahedron Lett., (1977) 1805.

6 For a comprehensive review, see: T.H. Chan and I. Fleming, Synthesis, (1979) 761.

7 J. Meijer, H. Westmijze and P. Vermeer, Recl. Trav. Chim. Pays-Bas, 95 (1976) 102.

8 H. Westmijze, H. Kleijn, J. Meijer and P. Vermeer, Recl. Trav. Chim. Pays-Bas, 100 (1981) 98.

9 J.K. Crandall and F. Collonges, J. Org. Chem., 41 (1976) 4089.

10 S.C. Watson and J.F. Eastham, J. Organomet. Chem., 9 (1967) 165.

$11 \mathrm{H}$. Westmijze and P. Vermeer, Synthesis, (1979) 390. 